\title{
Investigation of Transient Eye Closure associated with Bright light in the Patients with Intermittent Exotropia
}

\section{Won Jong Choi}

Seoul National University Hospital

\section{Yeonji Jang}

Seoul National University Hospital

\section{Seung-Joon Kim}

Seoul National University College of Medicine

Jae Ho Jung ( $\square$ jaeho.jung@snu.ac.kr)

Seoul National University College of Medicine https://orcid.org/0000-0003-4742-4903

\section{Research article}

Keywords: Eye closure, Intermittent exotropia, Photosensitivity, Photophobia

Posted Date: March 10th, 2021

DOI: https://doi.org/10.21203/rs.3.rs-294150/v1

License: (c) (i) This work is licensed under a Creative Commons Attribution 4.0 International License. Read Full License

Version of Record: A version of this preprint was published at BMC Ophthalmology on July 31st, 2021. See the published version at https://doi.org/10.1186/s12886-021-02046-7. 


\section{Abstract}

Background: To present a simple method to evaluate transient eye closure (TEC) under bright light using binocular pupillometry in children with intermittent exotropia (IXT).

Methods: Sixty-one children with IXT were studied using binocular pupillometry. Each patient was exposed to each phase as follows: scotopic phase (darkness) for 3,300 ms, mesopic phase for $200 \mathrm{ms,}$ scotopic phase for $3,300 \mathrm{~ms}$, low-intensity white light phase $\left(10 \mathrm{~cd} / \mathrm{m}^{2}\right)$ for $200 \mathrm{~ms}$, scotopic phase for $3,300 \mathrm{~ms}$, and high-intensity white light phase $\left(100 \mathrm{~cd} / \mathrm{m}^{2}\right)$ for $200 \mathrm{~ms}$. TEC was present if the subject closed eyes immediately more than half in response to light, compared with the one in the scotopic phase. We assessed the agreement between TEC and self-reporting photosensitivity, and also evaluated the associated factors for the presence of TEC in IXT patients.

Results: With the new method to evaluate TEC under different light intensities, 27 (44.3\%) of the 61 IXT patients showed TEC, and 34 (55.7\%) did not demonstrate TEC. TEC under high-intensity white light had a strong correlation with photosensitivity $(r=0.77)$. The smaller angle of deviation at near was associated with the presence of TEC, with statistical significance $(p=0.04)$. Normal sensory status at distance was significantly associated with TEC $(p<0.01)$. Multivariate analysis using multiple logistic regression analysis showed that normal sensory status was significantly associated with TEC $(p=0.02)$.

Conclusions: The test using binocular pupillometry is useful in identifying TEC related to bright light, and the presence of TEC was strongly correlated with photosensitivity in patients with IXT.

\section{Background}

Intermittent exotropia (IXT) is one of the most common types of childhood strabismus and occurs more frequently in Asian populations. ${ }^{1,2}$ Transient eye closure (TEC) in bright light or outdoor is a very common symptom in patients with IXT, and it can be a reason to present for ophthalmology evaluation. This symptom affects the patient's health-related quality of life, ${ }^{3}$ and it often persists even after successful strabismus surgery. ${ }^{4}$ Several studies have suggested that the mechanism of TEC is a decreased threshold of bright light, abnormal binocular summation, diplopia, or Fechner's paradox, which is, in brief, the apparent increase in the brightness of a figure caused by closing one eye after viewing the figure with both eyes open. ${ }^{4-7}$ Although many studies considered TEC and photosensitivity as synonyms, ${ }^{6,8-10}$ the association between TEC and photosensitivity is still unclear. In addition, there was no objective grading or quantification method to evaluate eye closure under bright light in IXT patients.

We now report a simple method to more objectively assess TEC evoked under different light intensities using binocular pupillometry. In addition, we evaluated the association between this new test method and self-reporting photosensitivity in patients with IXT and associated factors related to TEC.

\section{Methods}


This study was conducted at Seoul National University Children's Hospital between 2018 and 2019. The study was reviewed and approved by the Institutional Review Board of Seoul National University Hospital (2010-080-1164), Seoul, South Korea. All study procedures adhered to the tenets of the Declaration of Helsinki.

\section{Subjects}

Patients with IXT without intervention were included. All subjects underwent a complete ophthalmologic examination and TEC testing under different light intensities using a binocular pupillometer. We defined that a subject has photosensitivity if the patient reports photosensitivity and/or parents observe their child avoiding or complaining of brightness.

Each patient underwent a prism alternate cover test to measure the angle of deviation at distance $(5 \mathrm{~m})$ and near $(30 \mathrm{~cm})$ the target, along with the evaluation of the office-based control scale (CS) for each eye. The control scale ranges from 0 (IXT best control) to 5 (constant exotropia), ${ }^{11}$ and the control scale was divided into two groups for the analysis: 1 and 2 (well-controlled IXT), and 3-5 (poorly controlled IXT). Moreover, near $(40 \mathrm{~cm})$ stereoacuity was measured using the Fly Stereo Acuity Test with Lea symbols (Vision Assessment Co., Elk Grove Village, IL, USA) while wearing his or her best refractive correction. Worth's Four Dot (W4D) test was also performed for each patient for the evaluation of sensory status.

We used binocular pupillometry (Mon CV3, Metrovision, France) for the evaluation of TEC. The patient was exposed to each phase as follows: scotopic phase (darkness) for $3,300 \mathrm{~ms}$, mesopic phase (under room light without light stimulation) for $200 \mathrm{~ms}$, scotopic phase for 3,300 ms, low-intensity white light phase $\left(10 \mathrm{~cd} / \mathrm{m}^{2}\right)$ for $200 \mathrm{~ms}$, and high-intensity white light phase $\left(100 \mathrm{~cd} / \mathrm{m}^{2}\right)$ for $200 \mathrm{~ms}$. The stimulator was equipped with near-infrared illumination $(880 \mathrm{~nm})$ and a high-resolution near-infrared image sensor that allowed for the measurement of pupil diameter even in complete darkness. Images of the eyes and eyelids were acquired and processed in real time (30 images per second). TEC was supposed to be present if the subject closed eyes more than half in response to light, compared with the one in the scotopic phase (Fig. 1). The proprietary analysis software provided in the pupillometry automatically outlined the pupillary contour on the images, ensuring the accuracy of the measurements (accuracy $=0.1 \mathrm{~mm}$ ) under controlled illumination conditions. The presence of TEC was defined by a masked examiner (JHJ). TEC includes both monocular and binocular, and the examiner was masked to the presence of photosensitivity and TEC.

Subjects were excluded if they had conditions that could affect contrast sensitivity, such as amblyopia, anisometropia, refractive errors greater than \pm 3.00 diopters or astigmatism of more than \pm 1.50 diopters, constant exotropia, vertical deviation of $>5$ prism diopters, paralytic or restrictive exotropia, and/or known global developmental or neurological abnormalities. The exclusion criteria also included the inability to perform a binocular pupillometry test.

\section{Statistical analysis}


We analyzed the association between the TEC and self-reported photosensitivity using Pearson's chisquare test and Phi correlation test. For the evaluation of the relationship between sex, W4D test, photosensitivity, office-based control scale, and the TEC, we used cross tab analysis. To investigate the relationships between the onset of IXT, stereoacuity, dynamics of the pupil, and the TEC, we used a series of Student's t-tests. Then, for the multivariate analysis, the associated factors were analyzed using a multivariate binomial logistic regression test. All analyses were performed using SPSS software version 23.0 (SPSS, Inc., Chicago, IL, USA).

\section{Result}

Sixty-one patients with IXT were enrolled in this study. There were 26 females (42.6\%) and 35 males $(57.4 \%)$. The average age of the patients was 6.3 years. Other demographic features are shown in Table 1. 
Table 1

Association between clinical characteristics and transient eye closure (TEC) in intermittent exotropia patients.

\begin{tabular}{|c|c|c|c|c|}
\hline & $\begin{array}{l}\text { Overall } \\
(n=61)\end{array}$ & $\begin{array}{l}\text { Transient eye } \\
\text { closure }(+) \\
(n=27)\end{array}$ & $\begin{array}{l}\text { Transient } \\
\text { eye } \\
\text { closure } \\
(-) \\
(n=34)\end{array}$ & P-value \\
\hline $\begin{array}{l}\text { Age (years, } \\
\text { mean } \pm S D \text { ) }\end{array}$ & $\begin{array}{l}6.30 \pm \\
1.90\end{array}$ & $6.44 \pm 1.97$ & $\begin{array}{l}6.18 \pm \\
1.88\end{array}$ & 0.59 \\
\hline Sex & & & & \\
\hline $\begin{array}{l}\text { Male } \\
\text { Female }\end{array}$ & $\begin{array}{l}35 \\
(57.4 \%) \\
26 \\
(42.6 \%)\end{array}$ & $\begin{array}{l}17(63.0 \%) \\
10(37.0 \%)\end{array}$ & $\begin{array}{l}18 \\
(52.9 \%) \\
16 \\
(47.1 \%)\end{array}$ & 0.43 \\
\hline Onset (years,mean $\pm S D$ ) & $\begin{array}{l}4.13 \pm \\
2.13\end{array}$ & $4.07 \pm 1.94$ & $\begin{array}{l}4.18 \pm \\
2.29\end{array}$ & 0.85 \\
\hline $\begin{array}{l}\text { Photo-sensitivity } \\
\text { Yes } \\
\text { No }\end{array}$ & $\begin{array}{l}29 \\
(47.5 \%) \\
32 \\
(52.5 \%)\end{array}$ & $\begin{array}{l}23(74.1 \%) \\
4(25.9 \%)\end{array}$ & $\begin{array}{l}6 \\
(26.5 \%) \\
28 \\
(73.5 \%)\end{array}$ & $<0.01^{*}$ \\
\hline $\begin{array}{l}\text { Distance angle } \\
\text { (PD,mean } \pm \mathrm{SD})\end{array}$ & $\begin{array}{l}26.15 \pm \\
6.39\end{array}$ & $24.41 \pm 7.29$ & $\begin{array}{l}27.53 \pm \\
5.28\end{array}$ & 0.06 \\
\hline $\begin{array}{l}\text { Near angle }(P D, \\
\text { mean } \pm S D)\end{array}$ & $\begin{array}{l}24.67 \pm \\
7.38\end{array}$ & $22.37 \pm 7.87$ & $\begin{array}{l}26.50 \pm \\
6.51\end{array}$ & $0.03^{*}$ \\
\hline Control scale & & & & 0.66 \\
\hline $\begin{array}{l}1 \sim 2 \text { (well-control) } \\
3 \sim 5 \text { (poor-control) }\end{array}$ & $\begin{array}{l}49 \\
(80.3 \%) \\
12 \\
(19.7 \%)\end{array}$ & $\begin{array}{l}21(77.8 \%) \\
6(22.2 \%)\end{array}$ & $\begin{array}{l}28 \\
(82.4 \%) \\
6 \\
(17.6 \%)\end{array}$ & \\
\hline
\end{tabular}

*: statistical significance, W4D: Worth 4 dot test, SD; Standard deviation 


\begin{tabular}{|c|c|c|c|c|}
\hline & $\begin{array}{l}\text { Overall } \\
(n=61)\end{array}$ & $\begin{array}{l}\text { Transient eye } \\
\text { closure }(+) \\
(n=27)\end{array}$ & $\begin{array}{l}\text { Transient } \\
\text { eye } \\
\text { closure } \\
(-) \\
(n=34)\end{array}$ & P-value \\
\hline Distance W4D & & & & $<0.01^{*}$ \\
\hline $\begin{array}{l}\text { Normal } \\
\text { Abnormal }\end{array}$ & $\begin{array}{l}32 \\
(56.1 \%) \\
25 \\
(43.9 \%)\end{array}$ & $\begin{array}{l}20(76.9 \%) \\
6(23.1 \%)\end{array}$ & $\begin{array}{l}12 \\
(38.7 \%) \\
19 \\
(61.3 \%)\end{array}$ & \\
\hline $\begin{array}{l}\text { Near W4D } \\
\text { Normal } \\
\text { Abnormal }\end{array}$ & $\begin{array}{l}43 \\
(75.4 \%) \\
14 \\
(24.6 \%)\end{array}$ & $\begin{array}{l}21(80.8 \%) \\
5(19.2 \%)\end{array}$ & $\begin{array}{l}22 \\
(71.0 \%) \\
9 \\
(29.0 \%)\end{array}$ & 0.39 \\
\hline $\begin{array}{l}\text { Near stereoacuity } \\
\text { (arc sec, mean } \pm \text { SD) }\end{array}$ & $\begin{array}{l}63.65 \pm \\
75.32\end{array}$ & $75.42 \pm 103.51$ & $\begin{array}{l}53.77 \pm \\
37.95\end{array}$ & 0.32 \\
\hline
\end{tabular}

With the new method to evaluate TEC under different light intensities, 27 (44.3\%) of the 61 IXT patients showed TEC, and 34 (55.7\%) did not demonstrate TEC (Table 1). Among the 29 patients with photosensitivity, 23 patients $(79.3 \%)$ had TEC and six patients $(20.7 \%)$ were without TEC. Among the 32 patients without photosensitivity, four patients (12.5\%) had TEC, while 28 patients (87.5\%) were TECnegative. The Phi correlation coefficient of TEC under low intensity and self-reporting photosensitivity was 0.67 , and the TEC under high intensity and self-reporting photosensitivity was 0.77 .

For the analysis of the associated factors, we used the TEC test result from high-intensity light. Two out of 27 TEC-positive patients (7.4\%) reported diplopia, while 4 out of 34 TEC-negative patients $(11.8 \%)$ reported diplopia $(p=0.57)$. The motor alignment was related to the TEC; the smaller angle of deviation at near target was associated with the presence of TEC with statistical significance $(p=0.04)$. Sensory status was also related to the presence of TEC; normal sensory status at distance was associated with TEC with statistical significance $(p<0.01)$. The control scale was not a factor that affected TEC $(p=$ 0.84). Detailed statistics of TEC and photosensitivity are shown in Table 1 . There were no pupil dynamics factors that significantly affected TEC (Table 2). Multivariate analysis, using binomial logistic regression test, showed that normal sensory status at distance was significantly associated with TEC $(p=0.02)$. 
Table 2

Pupil dynamics and transient eye closure (TEC) using binocular pupillometry testing.

\begin{tabular}{|c|c|c|c|c|}
\hline Dynamics of pupil & & $\begin{array}{l}\text { Transient eye closure }(-) \\
\text { (mean } \pm \text { SD) }\end{array}$ & $\begin{array}{l}\text { Transient eye closure }(+) \\
\text { (mean } \pm \text { SD) }\end{array}$ & P-value \\
\hline \multirow[t]{2}{*}{ Initial diameter } & $\mathrm{R}$ & $5.26( \pm 0.81)$ & $5.71( \pm 0.27)$ & 0.14 \\
\hline & L & $5.35( \pm 0.71)$ & $5.69( \pm 0.22)$ & 0.18 \\
\hline \multirow[t]{2}{*}{ Amplitude of contraction } & $\mathrm{R}$ & $1.96( \pm 0.30)$ & $2.21( \pm 0.30)$ & 0.09 \\
\hline & L & $2.09( \pm 0.24)$ & $2.18( \pm 0.27)$ & 0.41 \\
\hline \multirow[t]{2}{*}{ Latency of contraction } & $\mathrm{R}$ & $193.6( \pm 35.47)$ & $198.3( \pm 74.15)$ & 0.85 \\
\hline & L & $191.0( \pm 35.81)$ & $202.3( \pm 75.45)$ & 0.66 \\
\hline \multirow[t]{2}{*}{ Duration of contraction } & $\mathrm{R}$ & $642.9( \pm 65.47)$ & $651.2( \pm 108.44)$ & 0.83 \\
\hline & $\mathrm{L}$ & $681.6( \pm 84.35)$ & $670.3( \pm 87.74)$ & 0.76 \\
\hline \multirow[t]{2}{*}{ Velocity of contraction } & $\mathrm{R}$ & $6.98( \pm 1.96)$ & $7.33( \pm 1.32)$ & 0.63 \\
\hline & $\mathrm{L}$ & $7.20( \pm 1.05)$ & $7.77( \pm 2.51)$ & 0.50 \\
\hline \multirow[t]{2}{*}{ Latency of dilation } & $\mathrm{R}$ & $836.5( \pm 78.86)$ & $849.5( \pm 54.80)$ & 0.66 \\
\hline & $\mathrm{L}$ & $881.6( \pm 72.72)$ & $862.8( \pm 65.91)$ & 0.53 \\
\hline \multirow[t]{2}{*}{ Duration of dilation } & $\mathrm{R}$ & $1,630.9( \pm 72.72)$ & $1,624.5( \pm 58.06)$ & 0.82 \\
\hline & $\mathrm{L}$ & $1,586.2( \pm 79.82)$ & $1,624.7( \pm 44.37)$ & 0.20 \\
\hline \multirow[t]{2}{*}{ Velocity of dilation } & $\mathrm{R}$ & $2.63( \pm 1.10)$ & $3.00( \pm 0.80)$ & 0.38 \\
\hline & $\mathrm{L}$ & $2.52( \pm 0.59)$ & $3.00( \pm 0.70)$ & 0.13 \\
\hline
\end{tabular}

\section{Discussion}

From a practical clinical standpoint, our new test method is useful in identifying the presence of TEC in patients with IXT. Binocular pupilometers are noninvasive test methods that use a Ganzfeld (Entire field) environment with a stimulator. Binocular pupillometry can monitor pupil changes under different light intensities, and can also observe eyelid movement simultaneously with changes in the pupil. This test method is easy to perform, even in children, without patient discomfort. The evaluation of TEC using binocular pupillometry can be an objective and repeatable test method to assess photosensitivity in patients with IXT. This test also provides data regarding TEC under different light intensity conditions; therefore, it may help grade the TEC in IXT patients and be an analytic tool when objective comparison of TEC is required. Using our new test method, we found that $44.3 \%$ of IXT patients had TEC evoked by 
bright light. The presence of TEC using binocular pupillometry showed strong agreement with selfreporting photosensitivity in IXT patients. In addition, multivariate analysis using a binomial logistic regression test showed that the angle of deviation at distance and near, stereopsis, presence of diplopia, and pupil dynamics had no significance with the presence of TEC, except for normal sensory status at distance.

Lew et al. suggested that photosensitivity and eye closure were more likely to occur in patients with a distance angle of strabismus $>25$ prism diopters. Moreover, the study revealed that these phenomena were found to disappear after strabismus surgery, even when the surgery was deemed under-corrected. ${ }^{4}$ However, in the study by $\mathrm{O}$ et al., the preoperative angle of deviation was not significantly different between those with a presence of squinting and those without squinting. ${ }^{6}$ Our present study found that, by individual analysis, the smaller angle of deviation at near was associated with the presence of TEC and the distance angle was not significantly associated with the presence of TEC, even though the motor status was not significant in multivariate analysis. A previous study recruited patients who underwent surgical correction while our study involved all patients with IXT who came to our clinic without any treatment. ${ }^{4}$ These discrepancies may be related to selection bias, as patients who required surgical treatment might have had more severe symptoms.

A previous study that analyzed 162 patients who underwent surgical correction also showed that squinting and/or photosensitivity were more likely to occur in patients with stereopsis worse than 60 seconds. ${ }^{4}$ However, Oh et al. revealed that stereopsis was not significantly associated with photosensitivity. ${ }^{6}$ This study also demonstrated that the degree of stereopsis was not related to the presence of TEC.

Pupils are the primary organs controlling retinal luminance, and abnormal pupil dynamics may cause photosensitivity. Dulop reported that there was abnormal pupil dynamic in patients with IXT; about onethird of patients with IXT have paradoxical pupil changes, and in these patients, pupil dilation occurs when the eyes are aligned immediately prior to exotropia. ${ }^{12}$ However, our study revealed that pupil dynamics, pupil size, and response to light stimulation were within normal ranges. In addition, there was no significant association between pupil dynamics and the presence of TEC, or photosensitivity.

TEC evoked by bright light intensity showed a strong correlation with self-reporting photosensitivity. Taken together, this study suggests that TEC may be a part of the light-modulating mechanism and an avoidance mechanism of photosensitivity. Therefore, we propose that TEC under bright light is a form of photic blink reflex. This reflexive eyelid movement is a naturally occurring response to light, and is controlled by neural circuits that exist in the brainstem. ${ }^{13}$ Photic blink reflex can function as an accessory pupil, further controlling retinal illuminance in addition to pupil size. ${ }^{14}$ Since this reflex has a shorter latency than the pupil light reflex, it may play a greater role in modulating retinal illuminance under both a light stimulus and a steady-state light. ${ }^{14,15} \mathrm{~A}$ photosensitivity grading study using a synoptophore, which measured subjective discomfort on a numeric scale, reported that the binocular photophobia threshold 
was significantly lower in participants reporting eye closure compared with those who did not. ${ }^{7}$ Campos et al. reported that a deterioration of fusional amplitude and a weakening of binocular sensory status were shown in patients with IXT during light exposure. ${ }^{8}$ They suggested that since bright light lowered the threshold of binocular photosensitivity, this impairment, although not conscious, may determine a subjective disturbance. To avoid this inconvenience, the patient may close one or both eyes, thereby eliminating any binocular demand. ${ }^{8}$ However, the study was performed by comparing the IXT group to a control group, which involved people with orthophoria, esophoria, and exophoria. Some IXT patients may have more deteriorated sensory status than normal people, and therefore, the investigations within the IXT group may show us more significant factors related to TEC. Our study demonstrated that normal sensory status was the only significant factor in the presence of TEC in patients with IXT. These findings suggest that the TEC phenomenon is independent of motor alignment, stereopsis, and pupil reflex pathway in patients with IXT.

Our method has some limitations. We did not calibrate the intensity of the light source, although there is a possibility that each patient has a different TEC threshold. Further research should be conducted to find the customized luminance intensity that accounts for more precise results. In addition, subgroup analysis was not performed. Subgroup analysis of the TEC-positive group without self-reporting photosensitivity and the TEC-negative group with self-reporting photosensitivity would provide us further information about this rather contradictive phenomenon. Nevertheless, the statistical significance of the association between subjective photosensitivity and binocular pupillometry was excellent. Finally, patients with IXT are more sensitive to light when they are outside. However, our TEC test was performed in the Ganzfeld environment, which might have caused the difference in the results.

In conclusion, this new test method using binocular pupillometry was objective in evaluating the presence of TEC and was particularly useful in grading TEC. TEC phenomenon may be associated with photosensitivity in patients with IXT. Our study results suggest that the TEC in patients with IXT is related to photic blink reflex, which may modulate independently with the angle of deviation, subnormal sensory status, and pupil dynamics.

\section{Abbreviations}

TEC; transient eye closure, IXT; intermittent exotropia, CS; control scale, W4D; Worth's four dot test, PACT: prism alternate cover test; PD: prism diopter

\section{Declarations}

\section{Ethics approval and consent to participate;}

This study was approved by the institutional research board (IRB) of the Seoul National University Hospital (SNUH, 2010-080-1164) and was performed in accordance with the ethical standards of the Declaration of Helsinki. All parents/guardians of minors included in the study provided verbal informed 
consent. As this study was conducted retrospectively and all data was anonymized, the written informed consent procedures have been exempted under the provisions of IRB of SNUH.

\section{Consent for publication;}

Not applicable for this study.

\section{Availability of data and materials;}

The datasets used and/or analyzed during the current study available from the corresponding author on reasonable request.

\section{Competing interests;}

The authors declare that they have no competing interest.

\section{Funding;}

This work was supported by the New Faculty Startup Fund from Seoul National University (JHJ).

\section{Authors' contributions;}

WJC and $\mathrm{JHJ}$ contributed to the design and writing of the manuscript. WJC and $\mathrm{JHJ}$ collected the data. SJK and JHJ performed the clinical examination and investigation. WJC and YJ shared in data analysis and interpretation and revised the intellectual content of the manuscript. All authors read and approved the final manuscript.

\section{Acknowledgements;}

Not applicable for this study.

\section{References}

1. Chia A, Roy L, Seenyen L. Comitant horizontal strabismus: an Asian perspective. Br J Ophthalmol. 2007;91:1337-40.

2. Matsuo T, Matsuo C. The prevalence of strabismus and amblyopia in Japanese elementary school children. Ophthal Epidemiol. 2005;12:31-6.

3. Hatt SR, Leske DA, Adams WE, Kirgis PA, Bradley EA, Holmes JM. Quality of life in intermittent exotropia: child and parent concerns. Arch Ophthalmol. 2008;126:1525-9.

4. Lew H, Kim CH, Yun YS, Han SH. Binocular photophobia after surgical treatment in intermittent exotropia. Optom Vis Sci. 2007;84:1101-3.

5. Lim SH, Hwang BS, Kim MM. Prognostic factors for recurrence after bilateral rectus recession procedure in patients with intermittent exotropia. Eye (Lond). 2012;26:846-52. 
6. Oh BL, Suh SY, Choung HK, Kim SJ. Squinting and photophobia in intermittent exotropia. Optom Vis Sci. 2014;91:533-9.

7. Wiggins RE, von Noorden GK. Monocular eye closure in sunlight. J Pediatr Ophthalmol Strabismus. 1990;27:16-20.

8. Campos EC, Cipolli C. Binocularity and photophobia in intermittent exotropia. Percept Mot Skills. 1992;74(3 Pt. 2):1168-70.

9. Chung SA, Rhiu S, Han SH, Lee JB. Photophobia measurement in intermittent exotropia using the contrast sensitivity test. Graefes Arch Clin Exp Ophthalmol. 2013;251:1405-11.

10. Kwon JM, Jung JH. Subnormal Binocular Contrast Sensitivity Summation in Patients with Intermittent Exotropia. J Korean Med Sci. 2018;33:e222.

11. Mohney BG, Holmes JM. An office-based scale for assessing control in intermittent exotropia. Strabismus. 2006;14:147-50.

12. Dunlop C. Ipsilateral pupil dilation associated with unilateral intermittent exotropia: a new observation. Clin Exp Ophthalmol. 2011;39:839-41.

13. Esteban A. A neurophysiological approach to brainstem reflexes. Blink reflex. Neurophysiol Clin. 1999;29:7-38.

14. Burr D. Vision: in the blink of an eye. Curr Biol. 2005;15:R554-6.

15. Katz BJ, Digre KB. Diagnosis, pathophysiology, and treatment of photophobia. Surv Ophthalmol. 2016;61:466-77.

\section{Figures}



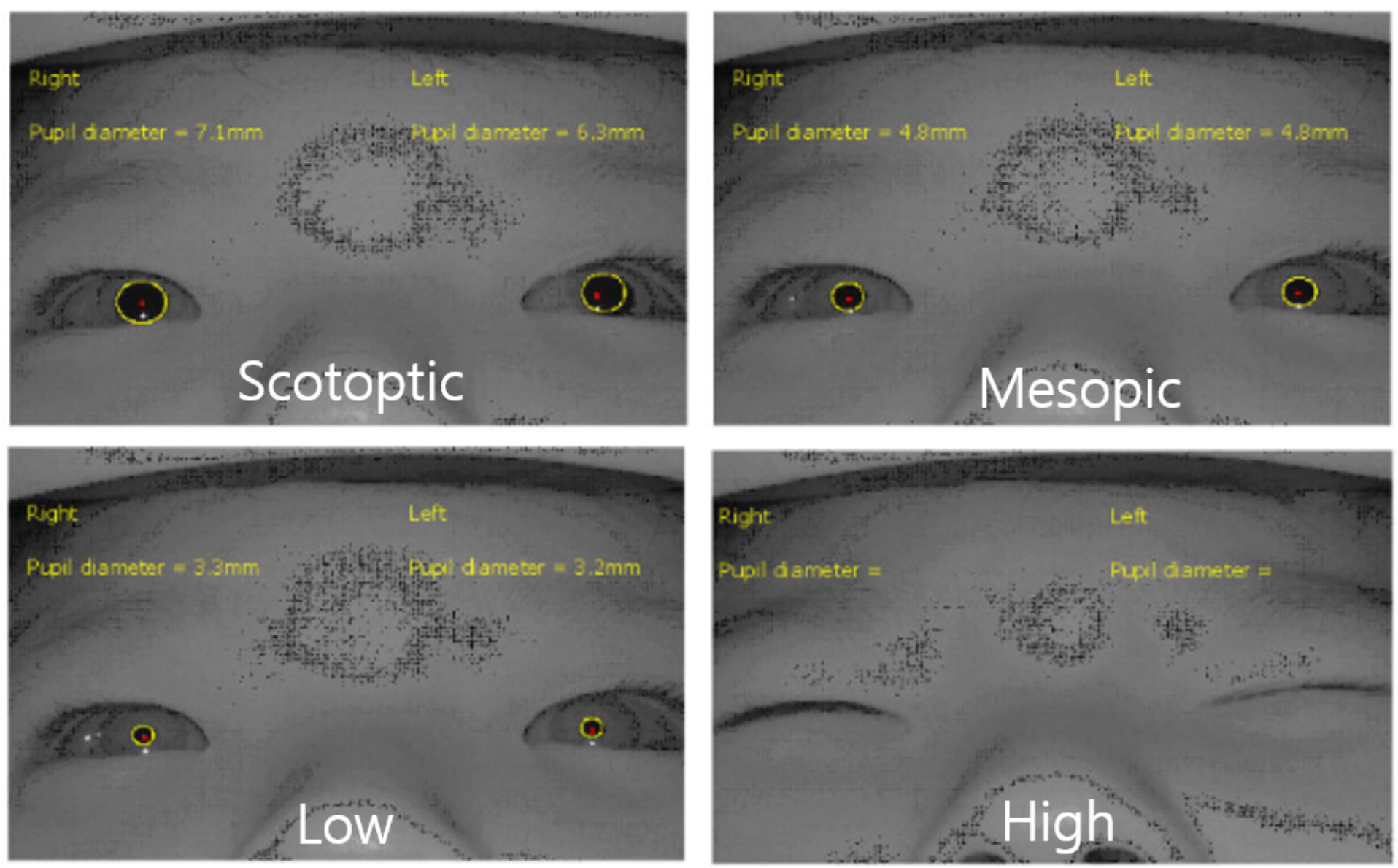

\section{Figure 1}

The photograph showed that pupil changes using binocular pupillometry (Mon CV3, Metrovision, France) with different light intensities were monitored. The eyelid closure associated with bright light is also monitored simultaneously with the pupil changes. 